\title{
The compound AST-003 could effectively promote apoptosis of renal cell carcinoma cells in vitro
}

\author{
Xingxing Tang^, Qiang Zhao, Jia Liu, Shuo Wang, Ning Zhang, Yong Yang^ \\ Key Laboratory of Carcinogenesis and Translational Research (Ministry of Education), Department of Urology, Peking University Cancer Hospital \\ \& Institute, Beijing, China \\ Contributions: (I) Conception and design: Y Yang, N Zhang; (II) Administrative support: Y Yang; (III) Provision of study materials or patients: X Tang, \\ Q Zhao, J Liu; (IV) Collection and assembly of data: X Tang, S Wang; (V) Data analysis and interpretation: X Tang; (VI) Manuscript writing: All \\ authors; (VII) Final approval of manuscript: All authors. \\ Correspondence to: Yong Yang, Ning Zhang. Key Laboratory of Carcinogenesis and Translational Research (Ministry of Education), Department of \\ Urology, Peking University Cancer Hospital \& Institute, No. 52 Fucheng Road, Haidian District, Beijing, China. Email: yoya_urology@sina.com; \\ niru7429@126.com.
}

Background: The toxicity of Sunitinib limits its clinical application. A new compound AST-003 was designed and synthesized based on the structure of Sunitinib, and previous study has confirmed that AST003 has the same efficacy and less toxicity as Sunitinib. We conducted this study to further verify the effect of AST-003 on renal cell carcinoma (RCC) cells in vitro and its mechanism.

Methods: Five RCC cell lines, A498, 786-0, SW-13, Caki-1 and ACHN, were used. Cells were treated with different concentrations of AST-003, and the effect of AST-003 on cell viability was detected by MTT assay and IC50 was determined. Blank control group and AST-003 group were set to evaluate the effect of AST-003 on cell apoptosis and cell cycle. The effect of AST-003 on cell protein expression was detected by western blot.

Results: After treatment with AST-003, the viability of the above five RCC cells was significantly inhibited. The IC50 of AST-003 on A498, 786-0, SW-13, Caki-1 and ACHN were 7.396, 6.592, 3.803, 12.05 and $3.422 \mu \mathrm{mol} / \mathrm{L}$, respectively. Compared with the blank control group, the apoptotic rates were $52.37 \%$ and $13.34 \%$ in A498 cells $(\mathrm{P}<0.001), 59.23 \%$ and $6.66 \%$ in $786-0$ cells $(\mathrm{P}<0.001), 45.67 \%$ and $4.19 \%$ in SW13 cells $(\mathrm{P}<0.001), 51.67 \%$ and $2.33 \%$ in Caki-1 cells $(\mathrm{P}<0.001), 55.40 \%$ and $5.50 \%$ in ACHN cells $(\mathrm{P}<0.001)$. Flow cytometry revealed that the proportion of cells in G0/G1 phase was significantly increased and the proportion of cells in S phase was significantly decreased in AST-003 group compared with blank control group, suggesting that AST-003 could block cells in G0/G1 phase. Western blot indicated that AST-003 could induce the up-regulation of the protein expression levels of apoptotic genes Caspase3, Caspase8, Caspase9, Bax and tumor suppressor p53, and inhibit the phosphorylation of STAT3, mTOR, AMPK and ERK, as well as the expression of Bcl-2, MKK, MKKK, c-jun and Ras proteins.

Conclusions: We found that AST-003 could effectively promote the apoptosis of RCC cells in vitro and block the cells in the intercellular phase, and its mechanism was similar to that of Sunitinib, suggesting that AST-003 has the value for further research.

Keywords: AST-003; sunitinib; metastatic renal cell carcinoma (RCC); toxicity.

Submitted Nov 27, 2020. Accepted for publication Mar 26, 2021.

doi: $10.21037 /$ tcr-20-3330

View this article at: http://dx.doi.org/10.21037/tcr-20-3330

^ ORCID: Xingxing Tang, 0000-0002-2499-5706; Yong Yang, 0000-0001-6934-0220. 


\section{Introduction}

Renal cell carcinoma (RCC) is a common urological malignancy, ranking seventh (male) and tenth (female) among all tumors in the United States in incidence (1), of which $75-85 \%$ are clear cell carcinomas (2). Approximately $33 \%$ of RCC patients would develop metastatic RCC (mRCC) (3). Since renal cancer is an angiogenic-rich tumor, anti-angiogenic tyrosine kinase inhibitor (TKI) is one of the main treatments for mRCC (4). Sunitinib is one of the representative drugs of TKI, and Food and Drug Administration (FDA) has approved it for the treatment of mRCC (5). However, due to its toxicity including hepatotoxicity and cardio-vascular toxicity, its clinical dose and efficacy have been greatly limited $(6,7)$. In recent years, some scholars have designed and synthesized a series of compounds AST-001, AST-002, AST-003 and AST-004 based on the structure of Sunitinib. Previous study has shown that AST-003 has similar in vitro tumor cell killing activity and stronger in vivo tumor growth inhibitory effect as Sunitinib, and has relatively lower toxicity (8). However, the effect of AST-003 on RCC cells in vitro was not described in detail in that study. Therefore, on the basis of that study, we conducted this study to further explore the effect and mechanism of AST-003 on RCC cells in vitro. We present the following article in accordance with the MDAR checklist (available at http://dx.doi.org/10.21037/ tcr-20-3330).

\section{Methods}

\section{Compounds preparation}

Sunitinib (SU11248) was purchased from Med Chem Express and AST-003 was provided by Professor Qing Li of Sun Yat-sen University in Guangzhou. According to the information provided, the preparation process of AST-003 was as follows: first, AST-004 was prepared, formaldehyde (30\%, $405 \mathrm{mg}, 5 \mathrm{mmol})$ and $\mathrm{Et}_{3} \mathrm{~N}(506 \mathrm{mg}, 5 \mathrm{mmol})$ were added to the dimethylformamide (DMF) $(14 \mathrm{~mL})$ solution of Sunitinib (0.5 g, $1.25 \mathrm{mmol})$, and the mixture was stirred overnight at room temperature. After cooling to $0{ }^{\circ} \mathrm{C}$ again, $\mathrm{H}_{2} \mathrm{O}$ was added to the mixture under stirring, the resulting yellow precipitate was filtered and collected, and dried in air to obtain Hydroxymethyl Sunitinib (AST004). Then 4-dimethylaminopyridine (DMAP) $(50 \mathrm{mg})$ and $(\mathrm{PhCO})_{2} \mathrm{O}(1.7 \mathrm{~g}, 7.7 \mathrm{mmol})$ were added to the Pyridine $(50 \mathrm{~mL})$ solution of AST-004 $(1.65 \mathrm{~g}, 3.86 \mathrm{mmol})$, and the mixture was stirred at room temperature overnight. After drying, saturated $\mathrm{NaHCO}_{3}$ solution $(20 \mathrm{~mL})$ was added and the solution was extracted twice with EtOAc $(20 \mathrm{~mL}$ each). The combined organic phase was dried (anhydrous $\mathrm{Na}_{2} \mathrm{SO}_{4}$ ), filtered, concentrated and purified by silica gel chromatography [with dichloromethane (DCM): $\mathrm{MeOH}$ $=10: 1]$ to obtain the yellow solid compound AST-003. AST003 and Sunitinib were dissolved in Dimethyl Sulphoxide (DMSO) to prepare a $10 \mathrm{mmol} / \mathrm{L}$ stock solution and stored in a $-20{ }^{\circ} \mathrm{C}$ refrigerator for use (8). The study was conducted in accordance with the Declaration of Helsinki (as revised in 2013). This study was approved by the Ethics Committee of Peking University Cancer Hospital (2017-2-4). As this study did not contain human trials, the requirement for informed consent was waived by the Ethics Committee.

\section{Cell lines}

To determine the effect of AST-003 on different RCC cells in vitro, we selected five kinds of human RCC cells, including A498, 786-0, SW-13, Caki-1 and ACHN, which were provided by Professor Qing Li of Sun Yat-sen University. The above cell lines were cultured in Dulbecco's Modified Eagle's Medium (DMEM) containing 10\% heat-inactivated Fetal Bovine Serum and 1\% Penicillin/ Streptomycin (Hyclone) and placed in a $37{ }^{\circ} \mathrm{C}$ incubator containing 5\% $\mathrm{CO}_{2}$. Cells were cultured in $16 \mathrm{~cm}^{2}$ flasks until cell confluence reached $80-90 \%$, then digested and passaged with $0.5 \%$ Trypsin. Cells in logarithmic growth phase were taken for experiments.

\section{Main reagents and instruments}

RPMI-1640 (SH30809.01B), DMEM (SH30243.01B), Fetal Bovine Serum (SH30084.03) were purchased from Hyclone Company. Phosphate-Buffered Saline (PBS) (C10010500BT) was purchased from Life Technologies. 3-(4, 5-dimethylthiazol-2-yl)-2, 5-diphenyltetrazolium bromide (MTT) (M5655-1G), Triton X-100 (T9284) were purchased from Sigma. Terminal-Deoxynucleotidyl Transferase Mediated Nick End Labeling (TUNEL) apoptosis detection kit (ATAK1001), Sodium Dodecyl Sulfate-Polyacrylamide Gel Electrophoresis (SDSPAGE) gel preparation kit and Glyceraldehyde-3Phosphate Dehydrogenase (GAPDH) (ATPA00013Rb) were purchased from Pujian Biological Company. Electrochemiluminescence (ECL) (K-12043-D10) was purchased from Wuhan Juneng Interpretation Biological Company. Bicinchoninic Acid (BCA) protein quantitative 
detection kit (P0009) was purchased from Biyuntian Company. Protein Pre-Staining Marker (61616) was purchased from Thermo Science. Apoptosis Detection Kit (A211-02) was purchased from Novozyme. RNase A solution (B500474) was purchased from Sangong Company. Propidium Iodide (PI) solution (421301) was purchased from Biolegend. Sheep anti-rabbit antibody (SA00001-2) and sheep anti-mouse antibody (SA00001-2) were purchased from Wuhan Sanying Company. Mitogen-activated Protein Kinase Kinase Kinase (MKKK) antibody, c-Jun antibody, Ras antibody were purchased from Abcam Company. Phosphorylated Signal Transducer and Activator of Transcription-3 (p-STAT3) antibody, Phospho-extracellular Signal-regulated Kinase (p-ERK) antibody, Phosphorylated Mammalian Target of Rapamycin (p-mTOR) antibody, Caspase3 antibody, Phosphorylated AMP-activated Protein Kinase- $\alpha$ (pAMPK- $\alpha$ ) (Thr172) antibody, Phosphorylated Nuclear Factor-kappa B (PNF-кB) p65 (Ser536) antibody, Phospho-MKK3 (Ser189)/MKK6 (Ser207) (22A8) antibody were purchased from CST. STAT3 antibody, Cytochrome C antibody, Poly (ADP-ribose) Polymerase (PARP) antibody, Caspase 8 antibody, Caspase 9 antibody, Bcl-2 antibody, Bax antibody, p65 antibody, Extracellular Signalregulated Kinase (ERK1/2) antibody, Mammalian Target of Rapamycin (mTOR) antibody, FasL antibody, p53 antibody, AMP-activated Protein Kinase- $\alpha 1$ (AMPK- $\alpha 1$ ) antibody, Tumor Necrosis Factor- $\alpha$ (TNF- $\alpha$ ) antibody were purchased from Proteintech. The full-function microplate detector (PerkinElmer) was purchased from PerkinElmer EnVision. Flow cytometry (CytoFLEX S) was purchased from Beckman Coulter. Gel imaging system (ChemiDoc ${ }^{\mathrm{TM}} \mathrm{XRS}+$ ) was purchased from Bio-Rad. Refrigerated centrifuge (Neofuge 15R), CO2 incubator (HF90), biological safety cabinet (HF-1200LC) were purchased from Heal Force. Inverted phase contrast microscopy (DP74) was purchased from Olympus. Electrothermal constant temperature water bath pot (HH-US-A) was purchased from American Standard Company. Electrophoresis apparatus (PP1152) and electrophoresis tank (MP-8001) were purchased from Cavoy Company. Decolorization shaker (TS-8S) was purchased from Qilinbeier Company. The ultrasonic crusher (JY92-IIN) was purchased from Xinzhi Company.

\section{Cytotoxicity test}

MTT assay was used to detect the effect of AST-003 on the proliferation and viability of RCC cells. Cells were seeded into 96-well plates, 7,000/well, and cultured at $37{ }^{\circ} \mathrm{C}$ for 48 hours. When the cells were adhered to the wall, $200 \mu \mathrm{L}$ of AST-003 and medium suspension were added into each well, and the concentrations of AST-003 were $0,1 / 27,1 / 9$, $1 / 3,1,3,9,27,81,243 \mu \mathrm{mol} / \mathrm{L}$, respectively, and cultured at $37{ }^{\circ} \mathrm{C}$ for $48 \mathrm{~h}$. Cells were then treated with $20 \mu \mathrm{L}$ MTT solution $(5 \mathrm{mg} / \mathrm{mL})$ for $4 \mathrm{~h}$, cultured at $37{ }^{\circ} \mathrm{C}$, and then $150 \mu \mathrm{L}$ DMSO was added to each well. Crystallization was dissolved by shaking for $10 \mathrm{~min}$, and then the absorbance of cells at $490 \mathrm{~nm}$ wavelength (OD value) was immediately detected by automatic microplate reader. With the blank medium reading value as the background, the cell viability was calculated, the cell growth curve was depicted, and the $\mathrm{IC}_{50}$ of AST-003 for different RCC cells was calculated.

\section{TUNEL apoptosis detection}

Cells were cultured in 24-well plates at $37{ }^{\circ} \mathrm{C}$ and $5 \% \mathrm{CO}_{2}$, with $5 \times 10^{4}$ cells per well. The cells were treated with drug the next day, and blank control group and AST-003 group were set up. The AST-003 group was added with AST-003, and the concentration in A498, 786-0, SW13, Caki-1 and ACHN cells were 7, 7, 4, 12 and $4 \mu \mathrm{mol} / \mathrm{L}$, respectively. Climbing slices were collected, washed with PBS for 5 minutes, fixed with $4 \%$ paraformaldehyde prepared with PBS for 30 minutes at room temperature, washed with PBS for 5 minutes, then permeated with PBS solution containing $0.1 \%$ TritonX-100 for 5-10 minutes, and finally washed with PBS three times for 5 minutes each time. The AST-003 group was added with $10 \mathrm{U} / \mathrm{mL}$ DNase I, and the blank control group was added with an equal volume of $1 \times$ DNase I Buffer. Both groups were added with $1 \times$ DNase I Buffer, and incubated in a wet box for 10 minutes. Remove the excess liquid, wash the slides thoroughly with deionized water for 3-4 times, and dilute the $10 \times$ reaction equilibrium solution with deionized water at 1:10 to $1 \times$ reaction equilibrium solution. TUNEL detection solution was prepared, then appropriate amount of TUNEL detection solution was added to each group of slices. After 60 minutes of incubation in a wet box in the dark, the slices were soaked twice in PBS solution at room temperature for 5 minutes each time, then the excess water on the slices was dried and $0.05 \mu \mathrm{g} / \mathrm{mL}$ of 4', 6-Diamidino-2-Phenylindole (DAPI) solution was dripped. The slices were incubated in a wet box in the dark for 10 minutes, soaked three times in PBS solution at room temperature for 5 minutes each time, sealed with anti-fluorescence quenching sealing agent, and 
observed under a fluorescence microscope.

\section{Flow cytometric apoptosis detection}

Cells were cultured in $24-$ well plates at $37^{\circ} \mathrm{C}$ and $5 \% \mathrm{CO}_{2}$, with $5 \times 10^{4}$ cells per well, then treated with drug the next day, and blank control group and AST-003 group were set up. The AST-003 group was added with AST-003, and the concentration in A498, 786-0, SW13, Caki-1 and ACHN cells were 7, 7, 4, 12 and $4 \mu \mathrm{mol} / \mathrm{L}$, respectively. Collect the cells, centrifuge at $1,000 \mathrm{rpm}$ for 5 minutes, absorb the supernatant, wash once with PBS, centrifuge at 1,000 rpm for 5 minutes again, absorb the supernatant, add Annevix Binding Buffer (10x) to dilute, take $100 \mu \mathrm{L}$ and resuspend, add $5 \mu \mathrm{L}$ Annevix fluorescein isothiocyanate (FITC), in the dark at room temperature for 10 minutes, add $5 \mu \mathrm{L}$ Annevix FITC, in the dark at room temperature for 15 minutes, then add $150 \mu \mathrm{L}$ Annevix Binding Buffer for flow cytometric apoptosis detection.

\section{Flow cycle detection}

Cells were cultured in $24-w e l l$ plates at $37{ }^{\circ} \mathrm{C}$ and $5 \%$ $\mathrm{CO}_{2}$, with $5 \times 10^{4}$ cells per well. The cells were treated with drug the next day, and blank control group and AST-003 group were set up. The AST-003 group was added with AST-003, and the concentration in A498, 786-0, SW13, Caki-1 and ACHN cells were 7, 7, 4, 12 and $4 \mu \mathrm{mol} / \mathrm{L}$, respectively. Cells were collected, centrifuged at 1,000 rpm for 5 minutes, washed once with PBS, centrifuged at $1,000 \mathrm{rpm}$ for another 5 minutes, and then resuspended with $100 \mu \mathrm{L}$ PBS. The cell suspension was added to pre-cooled Ethanol at $-20{ }^{\circ} \mathrm{C}$, fixed overnight at $4{ }^{\circ} \mathrm{C}$, centrifuged at 1,000 rpm for 5 minutes to remove Ethanol, washed once with PBS, and centrifuged at 1,000 rpm for 5 minutes to remove Ethanol. Finally, 200-300 $\mu \mathrm{L}$ of Deoxyribonucleic Acid (DNA) staining solution was added to each group, and placed the tubes in the dark for 15 minutes at room temperature for flow cycle detection.

\section{Western blots}

Cells were cultured in $10 \mathrm{~cm}$ dishes at $37{ }^{\circ} \mathrm{C}$ and $5 \% \mathrm{CO}_{2}$, at $2 \times 10^{6} \%$ well, and treated with AST-003 the next day. The concentration of AST-003 in A498, 786-0, SW13, Caki-1 and ACHN cells were 7, 7, 4, 12 and $4 \mu \mathrm{mol} / \mathrm{L}$, respectively. After 48 hours, the cells were collected for western blots. Discard the culture medium, wash once with PBS, add lysate into each hole, blow several to make the lysate and cells fully contact, and place horizontally on ice for lysis for 10-20 minutes. Collect the cell precipitation and lysate, centrifuge at $12,000 \mathrm{rpm} 4{ }^{\circ} \mathrm{C}$ for $3-5$ minutes. Transfer the supernatant to a new $1.5 \mathrm{~mL}$ Eppendorf (EP) tube, take $1-2 \mu \mathrm{L}$ for the detection of total protein content by BCA kit. Add appropriate volume of $5 \times$ Loading, mix well, and boil for 5 minutes. After SDS-PAGE electrophoresis, the electroformed polyvinylidene fluoride (PVDF) membrane was removed and washed once with tris buffered saline tween (TBST), sealed with $5 \%$ milk/TBST at room temperature for one hour, and rinsed with TBST for 2 minutes. The primary antibody was diluted with $1 \%$ bovine serum albumin (BSA)/PBST, and the membrane was sealed with a hybridization bag and refrigerated overnight at $4{ }^{\circ} \mathrm{C}$, then washed 3 times with PBST for 10 minutes each time. Then the PVDF membrane was placed in the secondary antibody labeled with Horseradish Peroxidase diluted with $5 \%$ Milk/PBST, incubated in a shaker at room temperature for one hour, and then washed three times with PBST for 10 minutes each time. Finally, equal amounts of Enhanced Luminol Reagent and Oxidizing Reagent diluted with appropriate amount of $\mathrm{ddH}_{2} \mathrm{O}$ were mixed and dripped onto the sealing membrane. The front of the PVDF film was touched down with the luminescent reagent, and the color was developed for 1.5-2 minutes, then the PVDF was turned over and the results were observed with a gel imaging system.

\section{Statistical analyses}

Statistical analyses were performed with Stata software (Version 15). The experimental data were expressed as mean and standard deviation. Comparisons between groups were performed using a two-tailed unpaired $t$-test. $\mathrm{P}$ values of $\left.<0.05\left(^{*}\right),<0.01\left(^{(* *}\right),<0.0011^{* * *}\right)$ were determined to be statistically significant.

\section{Results}

\section{Effect of AST-003 on proliferation viability of RCC cells}

MTT assay was used to detect cell viability after $48 \mathrm{~h}$ of drug treatment, and cell growth curve was plotted to calculate the $\mathrm{IC}_{50}$ data of each cell. MTT assay results showed that the proliferation viability of the above five RCC cells was significantly inhibited after treatment with AST-003, and as the increase of AST-003 concentration, 
A

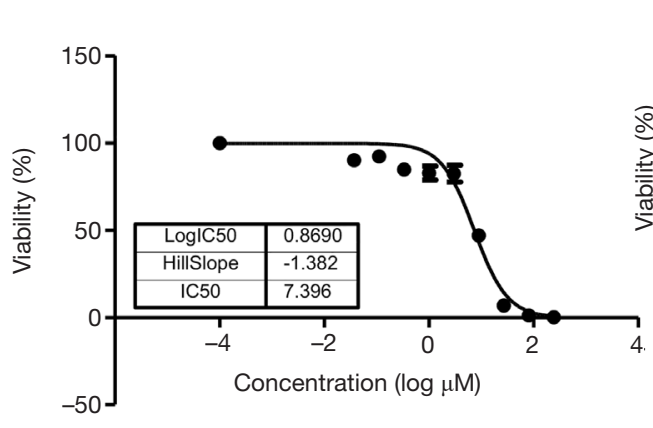

B

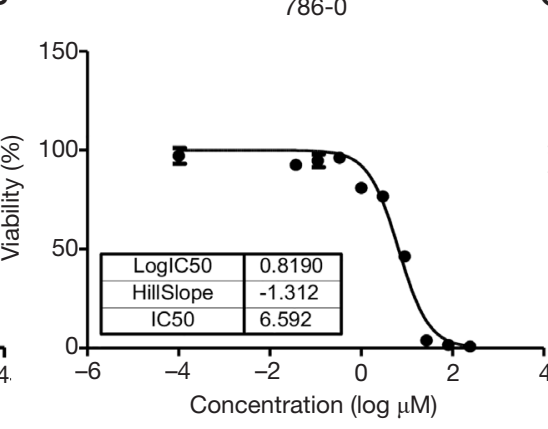

C

SW13

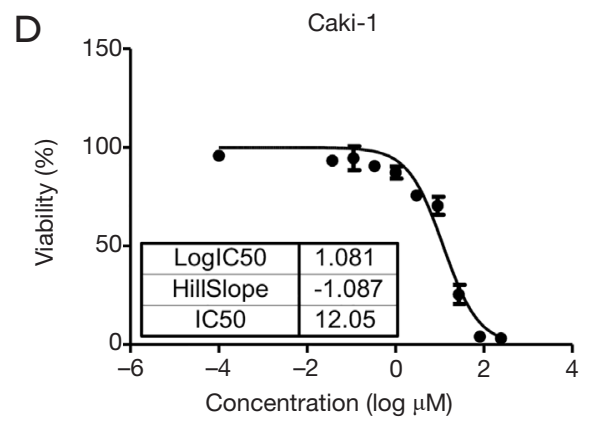

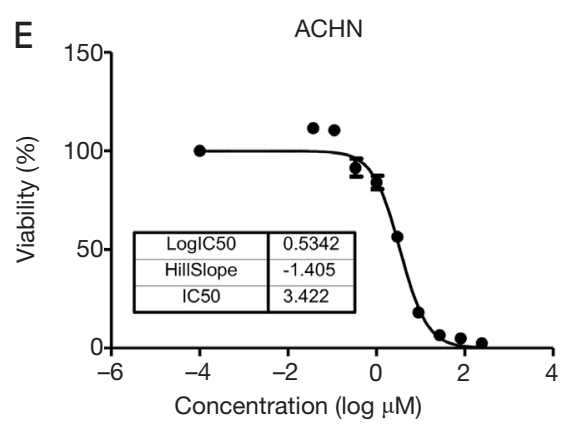

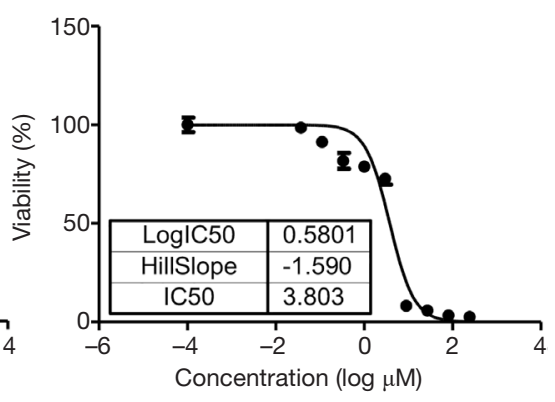

Figure 1 Effect of AST-003 on viability of renal cell carcinoma cells. After treatment with AST-003, the viability of the five renal cell carcinoma cells was significantly inhibited, and the inhibition was more obvious with the increase of AST-003 concentration in a concentration-dependent manner. The results showed that (A) the IC50 of AST-003 for A498 cells was 7.396 $4 \mathrm{~mol} / \mathrm{L}$, (B) the IC50 of AST003 for 786-0 cells was $6.592 \mu \mathrm{mol} / \mathrm{L}$, (C) the IC50 of AST-003 for SW13 cells was $3.803 \mu \mathrm{mol} / \mathrm{L}$, (D) the IC50 of AST-003 for Caki-1 cells was $12.050 \mu \mathrm{mol} / \mathrm{L}$, (E) the IC50 of AST-003 for ACHN cells was $3.422 \mu \mathrm{mol} / \mathrm{L}$.

the inhibitory effect was more obvious in a concentrationdependent manner. The results showed that the $\mathrm{IC}_{50}$ of AST-003 was $7.396 \mu \mathrm{mol} / \mathrm{L}$ for A498 cell, $6.592 \mu \mathrm{mol} / \mathrm{L}$ for $786-0$ cell, $3.803 \mu \mathrm{mol} / \mathrm{L}$ for SW13 cell, $12.05 \mu \mathrm{mol} / \mathrm{L}$ for Caki-1 cell and $3.422 \mu \mathrm{mol} / \mathrm{L}$ for ACHN cell. Figure 1 shows the effect of AST-003 on the proliferation viability of different RCC cells.

\section{Effect of AST-003 on apoptosis of RCC cells}

After treated with AST-003, DAPI stained cells were observed under ultraviolet light excitation of fluorescence microscopy. It was found that the cell membrane of the blank control group was intact, the chromatin was evenly distributed, and showed uniform diffuse bluewhite fluorescence. In AST-003 group, some cells showed chromatin condensation and breakage, while the cell membrane was intact and showed dense blue-white granular fluorescence, forming apoptotic bodies. In FITC stained cells, AST-003 group showed a large amount of green fluorescence, suggesting a large number of cell apoptosis, while blank control group only showed a small amount of green fluorescence, suggesting only a small number of cell apoptosis. TUNEL apoptotic test results showed that the proportion of apoptotic cells in AST-003 group was significantly increased compared with blank control group in all these five kind cells, suggesting that AST-003 could significantly promote RCC cells apoptosis (Figure 2).

The results of flow cytometry were shown in Table 1. The apoptotic rates of AST-003 group and blank control group in A498 cells were $52.37 \%$ and $13.34 \%(\mathrm{P}<0.001)$, in 786 0 cells were $59.23 \%$ and $6.66 \%(\mathrm{P}<0.001)$, in $\mathrm{SW} 13$ cells were $45.67 \%$ and $4.19 \%(\mathrm{P}<0.001)$, in Caki-1 cells were $51.67 \%$ and $2.33 \%(\mathrm{P}<0.001)$, in ACHN cells were $55.40 \%$ and $5.50 \%(\mathrm{P}<0.001)$, respectively. In all cell lines, AST003 group showed significant increase in the proportion of apoptotic cells, suggesting that AST-003 could effectively promote RCC cell apoptosis (Figure 3). 


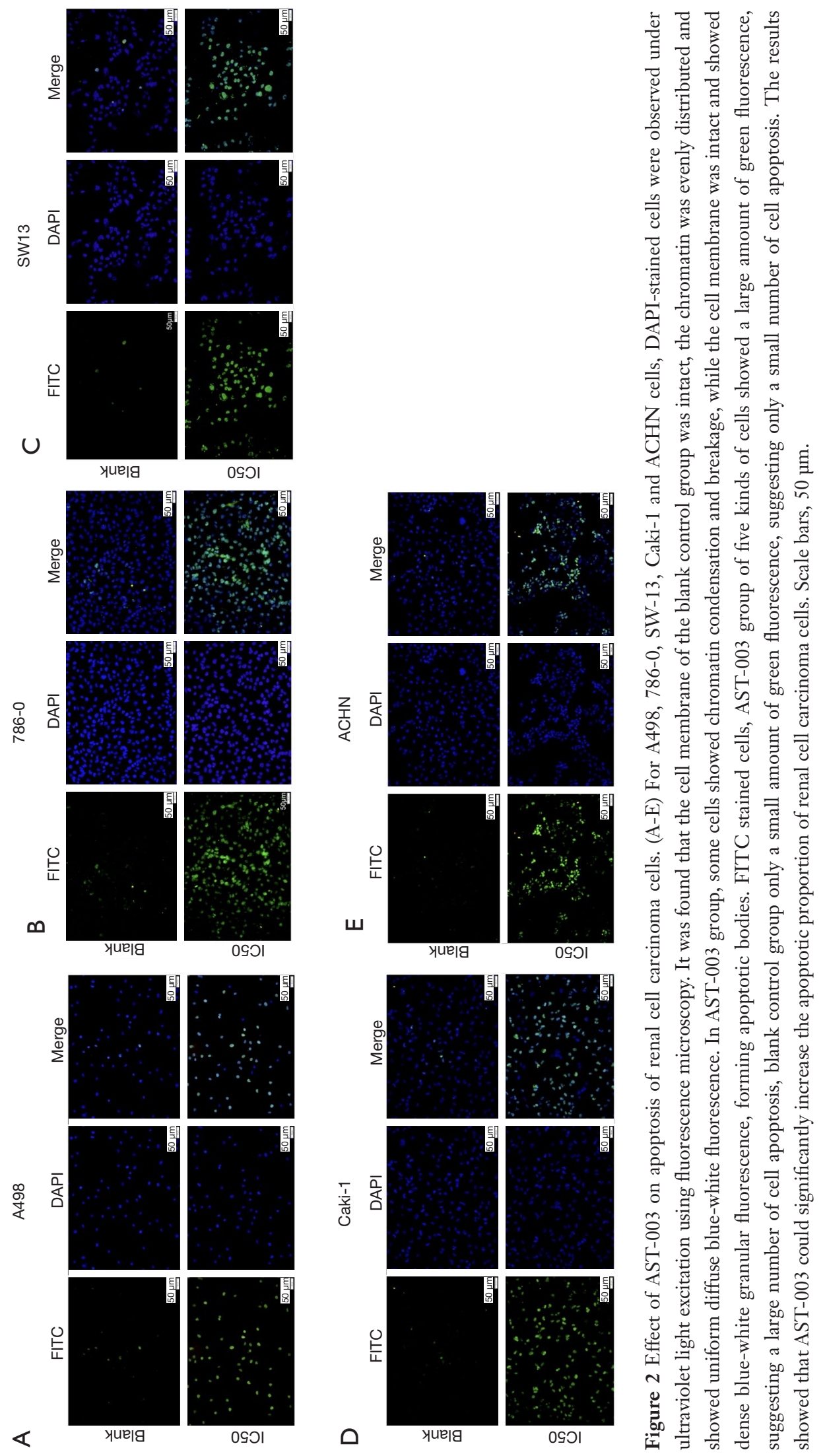


Table 1 Effect of AST-003 on apoptosis of renal cell carcinoma cells

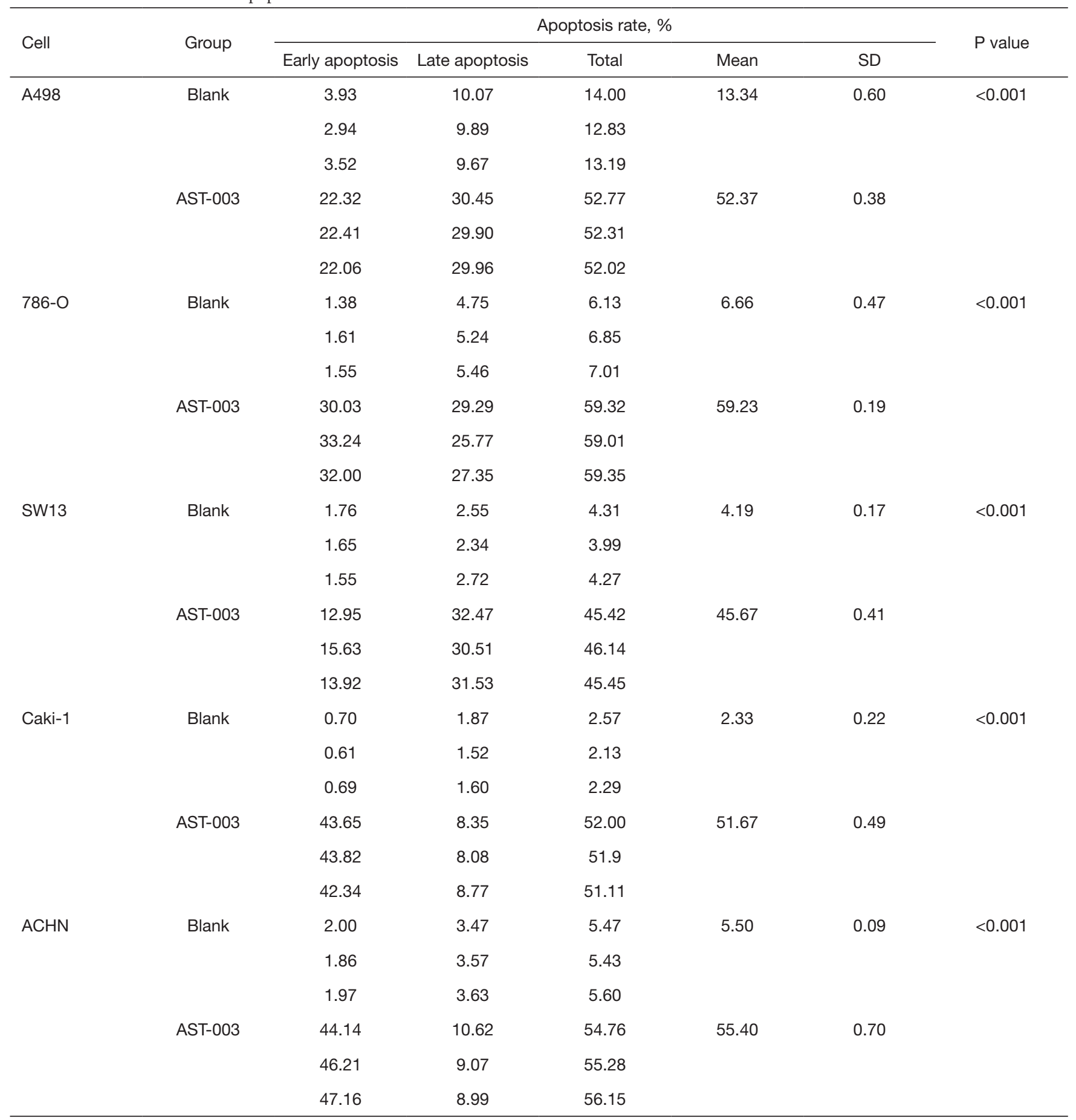

$\mathrm{SD}$, standard deviation. 
A

A498

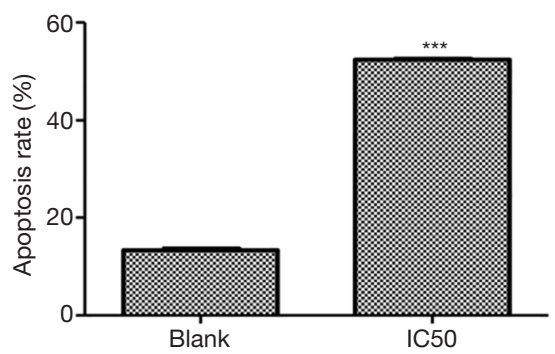

D

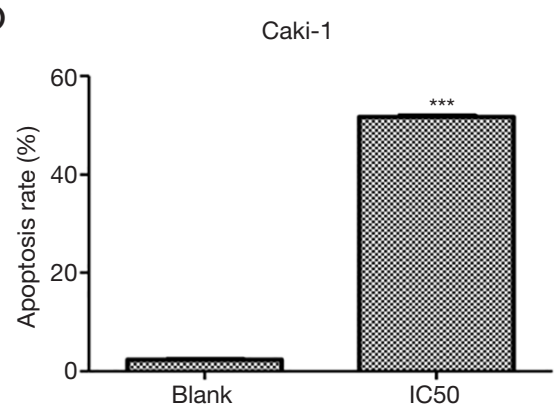

B

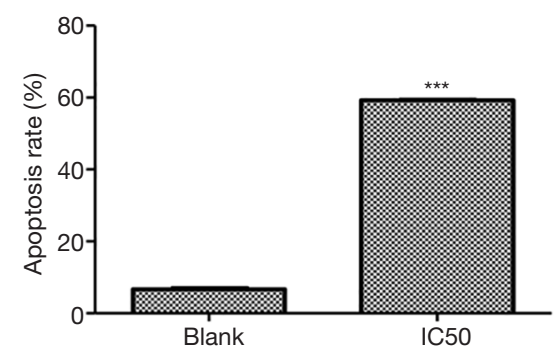

E

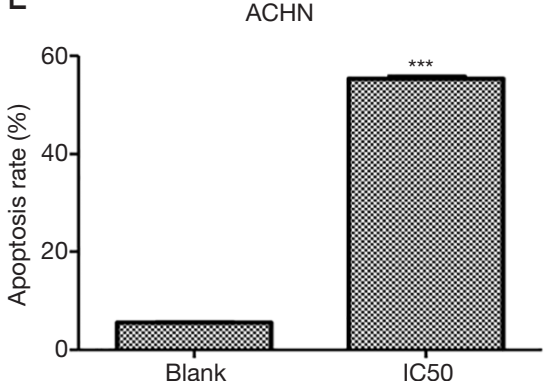

C

SW13

Figure 3 Effect of AST-003 on apoptosis of renal cell carcinoma cells. (A) In A498 cells the apoptosis rates of AST-003 group and blank control group were $52.37 \%$ and $13.34 \%(\mathrm{P}<0.001)$. (B) In 786-0 cells, the apoptotic rates of AST-003 group and blank control group were $59.23 \%$ and $6.66 \%(\mathrm{P}<0.001)$. (C) In SW13 cells, the apoptosis rates of AST-003 group and blank control group were 45.67\% and $4.19 \%$ $(\mathrm{P}<0.001)$. (D) In Caki-1 cells the apoptosis rates of AST-003 group and blank control group were 45.67\% and 4.19\% (P<0.001). (E) In ACHN cells the apoptosis rate of AST-003 group and blank control group was $55.40 \%$ and $5.50 \%(\mathrm{P}<0.001)$. In all cell lines, the proportion of apoptotic cells in AST-003 group was significantly higher than that in blank control group, suggesting that AST-003 could effectively promote the apoptosis of RCC cells. ${ }^{* * *} \mathrm{P}<0.001$.

\section{Effect of AST-003 on cell cycle of RCC cells}

The results of flow cytometry are shown in Table 2. In A498 cells, the proportion of cells in G0/G1 phase in AST-003 group was significantly higher than that in control group (57.10\% vs. $47.38 \%, \mathrm{P}<0.001$ ), and the proportion of cells in $\mathrm{S}$ phase was significantly lower than that in control group $(14.09 \%$ vs. $25.19 \%, \mathrm{P}<0.001)$. In $786-0$ cells, the proportion of cells in G0/G1 phase in AST-003 group was significantly higher than that in control group $(65.53 \%$ vs. $59.12 \%, \mathrm{P}<0.001)$, and the proportion of cells in $\mathrm{S}$ phase was significantly lower than that in control group $(8.00 \%$ vs. $13.96 \%, \mathrm{P}=0.041$ ). In $\mathrm{SW} 13$ cells, the proportion of cells in G0/G1 phase in the AST-003 group was significantly higher than that in the control group $(61.22 \%$ vs. $54.24 \%$, $\mathrm{P}<0.001$ ), and the proportion of cells in $\mathrm{S}$ phase was significantly lower than that in the control group $(10.25 \%$ vs. $20.38 \%, \mathrm{P}<0.001)$. In Caki-1 cells, the proportion of cells in G0/G1 phase in AST-003 group was significantly higher than that in control group $(72.08 \%$ vs. $64.92 \%, \mathrm{P}<0.001)$, and the proportion of cells in $\mathrm{S}$ phase was significantly lower than that in control group $(2.64 \%$ vs. $11.74 \%$, $\mathrm{P}<0.001)$. In ACHN cells, the proportion of cells in G0/G1 phase in AST-003 group was significantly higher than that in control group $(74.89 \%$ vs. $68.33 \%, \mathrm{P}=0.002)$, and the proportion of cells in $\mathrm{S}$ phase was significantly lower than that in control group ( $7.65 \%$ vs. $8.97 \%, \mathrm{P}=0.048)$. In all these RCC cells, compared with the blank control group, the proportion of cells in G0/G1 phase in AST-003 group was significantly increased, while the proportion of cells in $\mathrm{S}$ phase was significantly decreased, suggesting that AST003 could block the cells in G0/G1 phase, reduce the rate of cell division and proliferation (Figure 4).

\section{Effect of AST-003 on protein expression in RCC cells}

The effect of AST-003 on RCC cell protein expression in 
Table 2 Effect of AST-003 on cell cycle of renal cell carcinoma cells

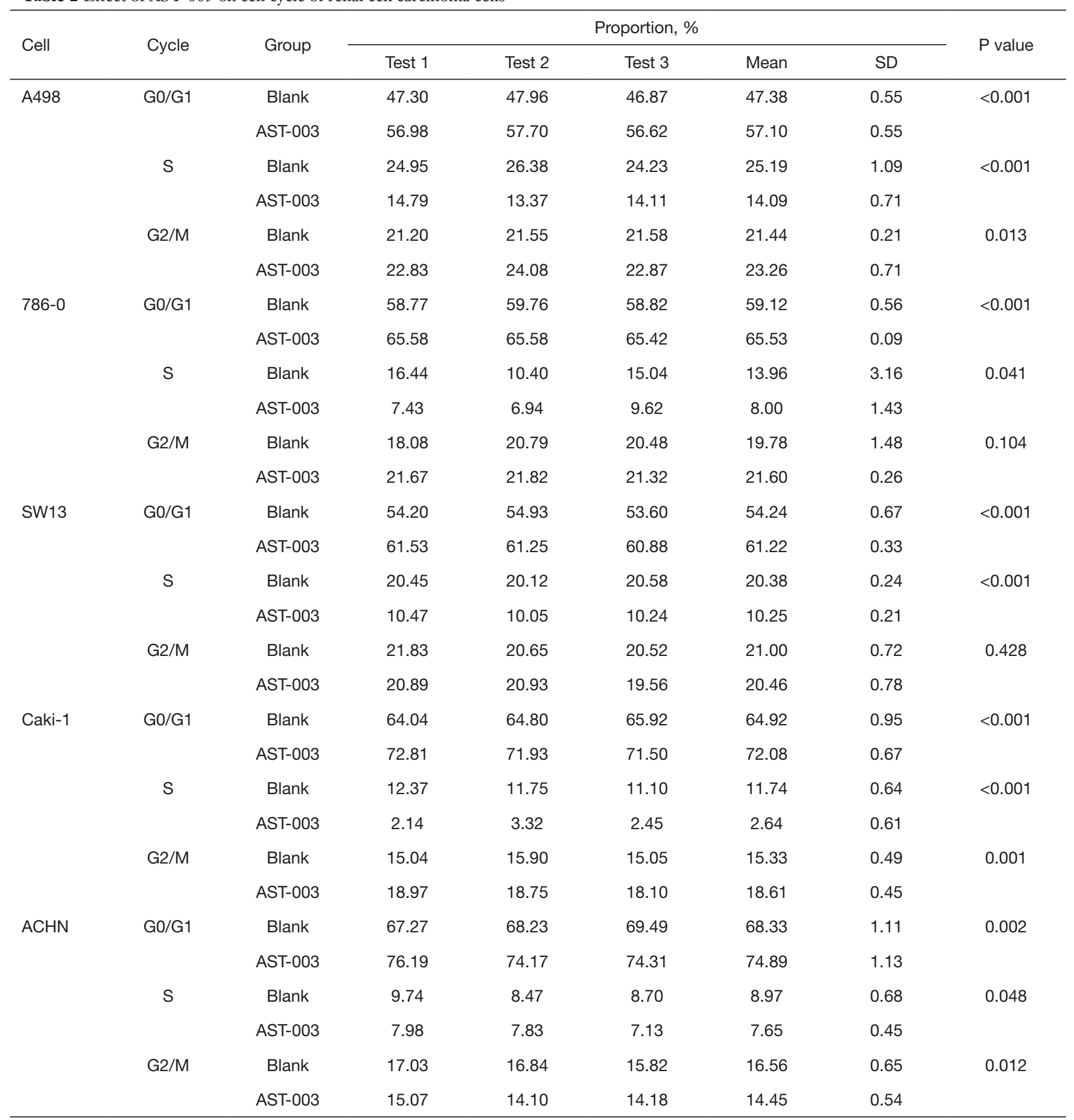

SD, standard deviation. 
A

A498

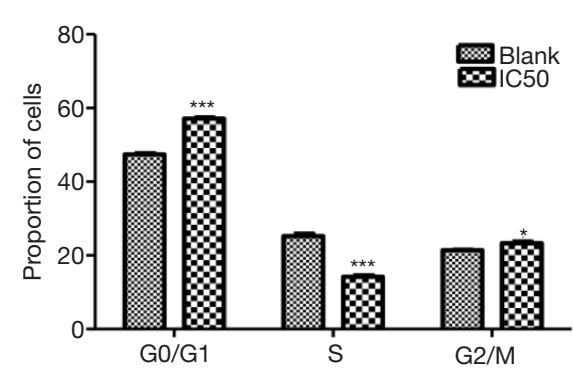

D

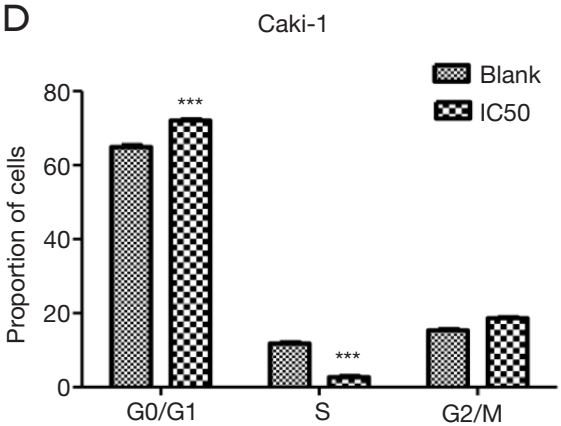

B

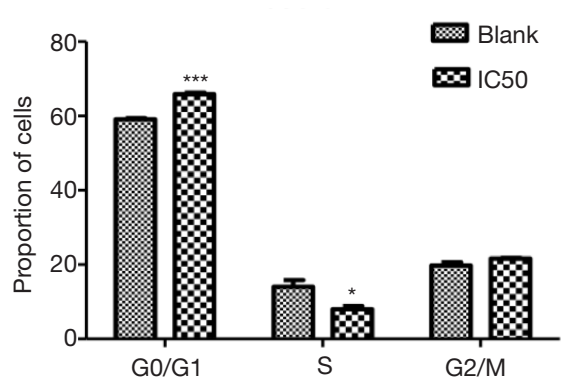

E

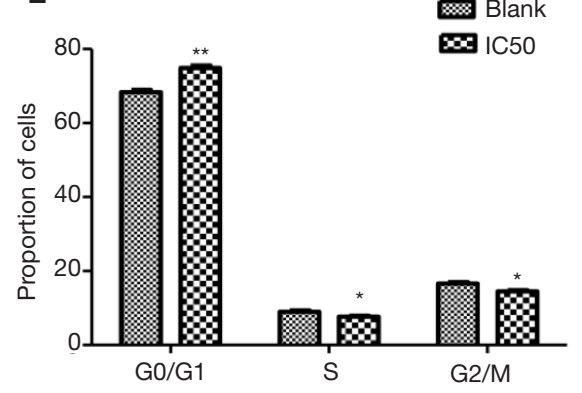

C SW13

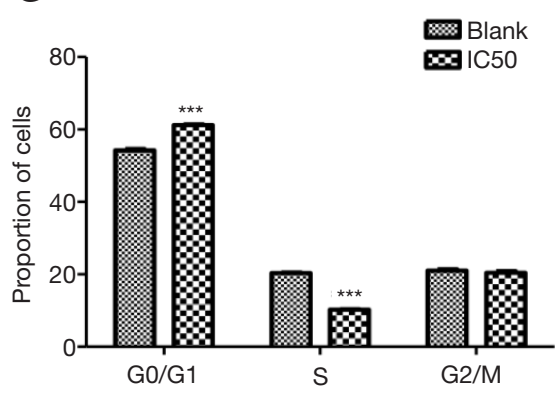

Figure 4 Effect of AST-003 on cell cycle of renal cell carcinoma cells. (A) In A498 cells, the proportion of cells in G0/G1 phase in AST003 group was significantly higher than that in control group $(57.10 \%$ vs. $47.38 \%, \mathrm{P}<0.001)$, and the proportion of cells in $\mathrm{S}$ phase was significantly lower than that in control group (14.09\% vs. $25.19 \%, \mathrm{P}<0.001)$. (B) In $786-0$ cells, the proportion of cells in G0/G1 phase in AST-003 group was significantly higher than that in control group (65.53\% vs. $59.12 \%, \mathrm{P}<0.001)$, and the proportion of cells in $\mathrm{S}$ phase was significantly lower than that in control group (8.00\% vs. 13.96\%, P=0.041). (C) In SW13 cells, the proportion of cells in G0/G1 phase in the AST-003 group was significantly higher than that in the control group (61.22\% vs. $54.24 \%, \mathrm{P}<0.001)$, and the proportion of cells in $\mathrm{S}$ phase was significantly lower than that in the control group (10.25\% vs. 20.38\%, $\mathrm{P}<0.001)$. (D) In Caki-1 cells, the proportion of cells in G0/G1 phase in AST-003 group was significantly higher than that in control group $(72.08 \%$ vs. $64.92 \%, \mathrm{P}<0.001)$, and the proportion of cells in $\mathrm{S}$ phase was significantly lower than that in control group (2.64\% vs. $11.74 \%, \mathrm{P}<0.001)$. (E) In ACHN cells, the proportion of cells in G0/G1 phase in AST-003 group was significantly higher than that in control group (74.89\% vs. $68.33 \%$, $\mathrm{P}=0.002)$, and the proportion of cells in $\mathrm{S}$ phase was significantly lower than that in control group (7.65\% vs. 8.97\%, $\mathrm{P}=0.048)$. It is suggested that AST-003 could block RCC cells in G0/G1 phase. ${ }^{*} \mathrm{P}<0.05,{ }^{* *} \mathrm{P}<0.01,{ }^{* * *} \mathrm{P}<0.001$.

vitro was qualitatively analyzed using Western Blot. The results showed that compared with the control group, AST-003 could induce the up-regulation of the protein expression levels of apoptotic genes Caspase3, Caspase8, Caspase9, Bax and tumor suppressor p53, and inhibit the phosphorylation of STAT3, mTOR, AMPK and ERK, as well as the expression of Bcl-2, MKK, MKKK, c-jun and Ras proteins, while there was no significant change in the expression of Cytochrome C, PARP, p65, TNF- $\alpha$ and FasL in the above five cells with GAPDH as the internal reference (Figure 5).

\section{Discussion}

Tumor growth depends on nutrients transported by blood vessels, and relevant studies have confirmed that angiogenesis is of great importance in the occurrence and development of tumors (9), while Receptor Tyrosine Kinase (RTK) plays an important role in tumor angiogenesis (10), and in a series of signal transduction pathways in cell cycle. Many types of tumors induce the growth, proliferation and differentiation of tumor cells via the dysfunction of RTK (11). Vascular Endothelial Growth Factor Receptor 


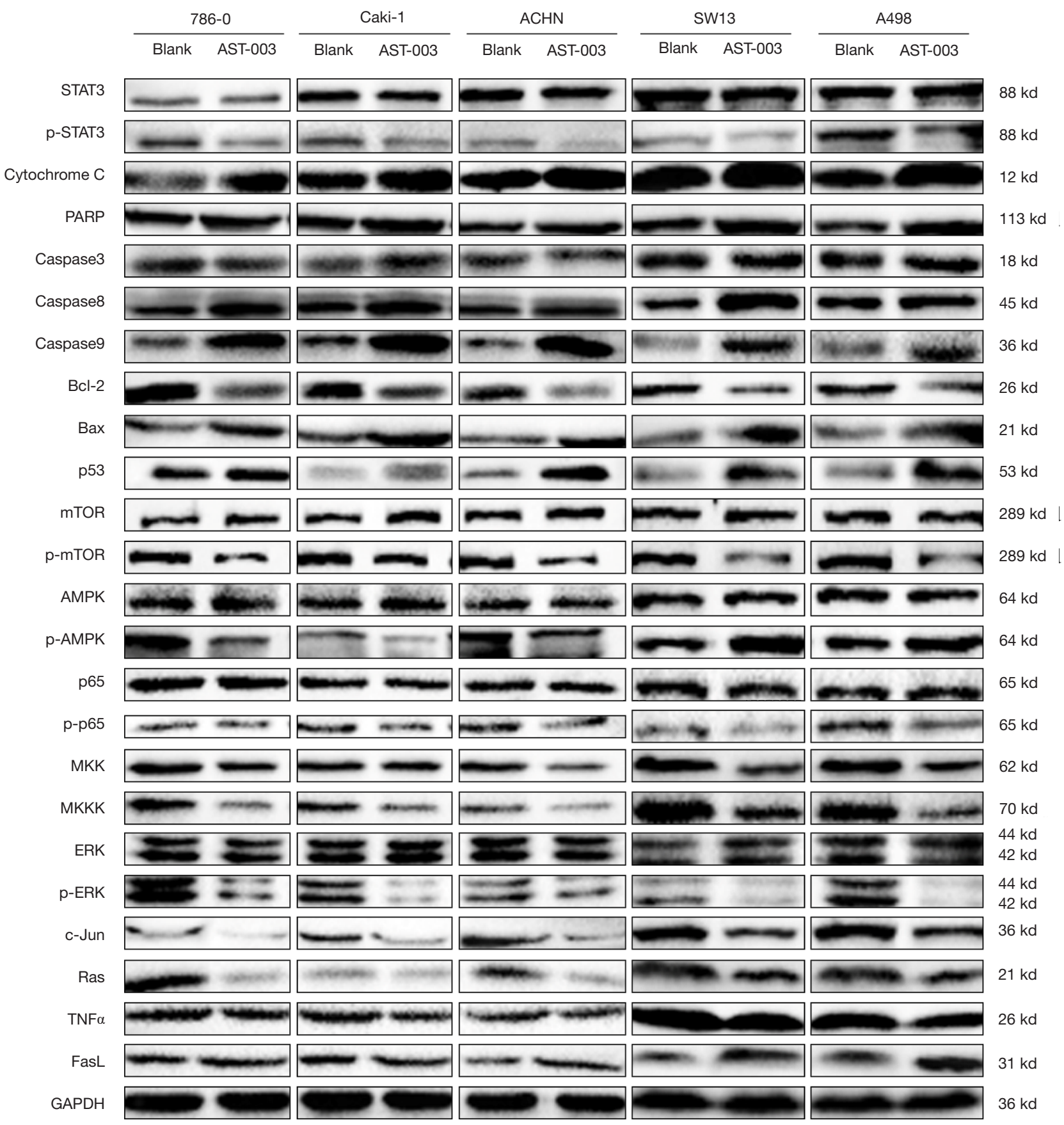

Figure 5 The effect of AST-003 on protein expression in renal cell carcinoma cells. The results showed that with GAPDH as the internal reference, AST-003 could induce the up-regulation of the protein of apoptotic genes Caspase3, Caspase8, Caspase9, Bax and tumor suppressor p53, inhibit the phosphorylation of STAT3, mTOR, AMPK and ERK, and inhibit the expression of Bcl-2, MKK, MKKK, c-jun and Ras. 


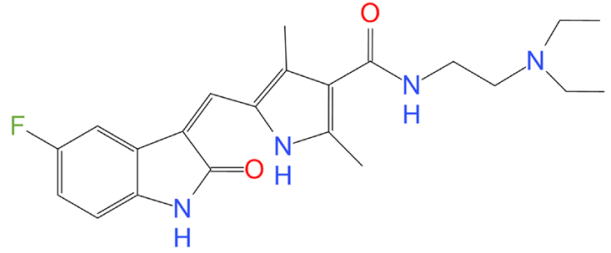

Sunitinib

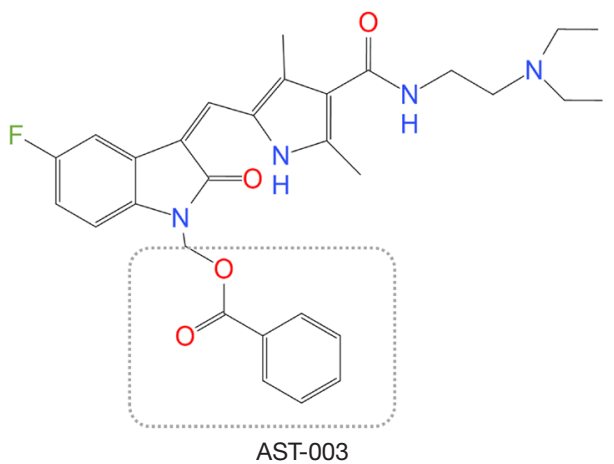

Figure 6 Comparison of the molecular structures of Sunitinib and AST-003. The main difference between the two is that AST-003 has an additional group (within the dotted frame) on the basis of the molecular structure of Sunitinib. AST-003 is less stable than Sunitinib, resulting in lower tissue concentrations and less toxicity.

(VEGFR) has tyrosine kinase activity, can activate intracellular signaling pathways, and ultimately cause tumor angiogenesis (12). Platelet-Derived Growth Factor Receptor (PDGFR) also has tyrosine kinase activity and is overexpressed in many tumors. During tumor proliferation, PDGFR is upregulated, stimulating the growth and proliferation of stromal cells and fibroblasts around endothelial cells $(11,13)$.

Sunitinib, as a multi-targeted TKI, can block both the VEGFR and PDGFR signal transduction pathways, thus achieving a stronger anti-angiogenesis effect. In addition, Sunitinib can also inhibit other RTKs, such as basic Fibroblast Growth Factor (bFGF), Fetal Liver Kinase 3 (Flk3) and cytokine receptor (c-Kit) (14). Clinical studies have confirmed that Sunitinib can effectively increase the survival of patients with mRCC and reduce the tumor volume, and it was approved by the FDA in 2006 for the treatment of mRCC (5). In the field of renal cancer, because advanced renal cancer is insensitive to radiotherapy and chemotherapy, Sunitinib treatment is of great significance (15). However, the limitations of Sunitinib are also very obvious, which has greater cardiotoxicity, and can also lead to hypertension, hand-foot syndrome, bone marrow suppression, thyroid dysfunction, etc. $(6,7,16)$. Although Sunitinib is generally safe, these toxic side effects still limit the clinical use of Sunitinib, and even some patients have to discontinue treatment because they cannot tolerate the toxicity.

Because Sunitinib acts as a multi-targeting TKI and participates in multiple cell signal pathways in vivo, the mechanism of these toxicities is not completely clear at present. Some studies suggest that these toxicities may be mainly related to the blockage of multiple signaling pathways, impaired angiogenesis, blockage of Nitric Oxide (NO) pathway, oxidative stress, etc. (17) or may also be related to the characteristics of its high tissue distribution (18). Therefore, it is possible to reduce the occurrence of related toxicity by reducing the distribution concentration in tissues. To this end, a team led by Professor Qing Li, Sun Yat-sen University, China, used a prodrug strategy to modify Sunitinib, designed and synthesized four compounds, AST-001, AST-002, AST-003, AST-004, and finally found that AST-003 produced better efficacy in tumor xenograft models while also improving the tolerance of mice (8). Figure 6 shows the comparison of the molecular structures of Sunitinib and AST-003. The main difference between the two is that AST-003 has an additional group on the basis of the molecular structure of Sunitinib. In terms of safety, previous study has shown that AST-003 is less stable in vivo than Sunitinib, and therefore has lower tissue concentrations and less toxicity. Animal experiment has confirmed that mice treated with AST-003 had lower levels of Sunitinib at the end of the 2-week treatment period. Lower tissue exposure doses resulted in better tolerance, and short-term high-dose experiment showed that mice tolerated AST-003 at least twice as much as Sunitinib. In terms of efficacy, although the tissue distribution concentration of AST-003 was lower than that of Sunitinib, the efficacy was superior to that of Sunitinib. At high doses (45 mg/kg), both AST-003 and Sunitinib could completely inhibit tumor growth, but at lower doses (5 and $15 \mathrm{mg} / \mathrm{kg}$ ), AST-003 had a stronger inhibitory effect on tumor growth than Sunitinib. AST-003 also produced higher efficacy in tumor xenograft models, suggesting that AST-003 could 
kill cells faster and irreversibly. Stronger efficacy and lower tissue stability resulted in significantly lower tissue exposure of AST-003 than Sunitinib, thus significantly lower toxicity (8).

A series of compounds were synthesized and AST003 was found in previous study (8). However, in vitro experiments, only morphological changes of treated RCC cells were described in that study. On the basis of that study, we further studied the effect of AST-003 on RCC cells in vitro, detected the $\mathrm{IC}_{50}$ of AST-003 on different RCC cells, and explored the possible mechanism of AST003 promoting apoptosis from the perspective of cell cycle and protein expression. We included A498, 786-0, SW-13, Caki-1 and ACHN, five common RCC cells, and analyzed the $\mathrm{IC}_{50}$ of AST-003 for different cells. The results showed that AST-003 had the strongest inhibitory effect and the lowest $\mathrm{IC}_{50}$ on $\mathrm{ACHN}$, and the highest $\mathrm{IC}_{50}$ for Caki-1. Apoptosis test confirmed that AST-003 could significantly promote the apoptosis of RCC cells. Flow cytometric detection indicated that the proportion of cells in G0/G1 phase was significantly increased and the proportion in $\mathrm{S}$ phase was significantly decreased after AST-003 treatment, which confirmed that AST-003 could block the cells in G0/ G1 phase. Thus, it can be seen that AST-003 has a proapoptotic effect on five kinds of RCC cells.

To clarify the mechanism of AST-003 promoting RCC cell apoptosis, we analyzed the effect of AST-003 on RCC cell protein expression. Previous in vitro cell study showed that AST-003 could significantly inhibit the phosphorylation of STAT3 and also reduce the phosphorylation of many downstream signaling proteins, including MEK, ERK and AKT (8). Our study confirms again that, like Sunitinib, AST-003 can effectively inhibit STAT3 signaling pathway while inhibiting the phosphorylation of ERK signaling protein, suggesting that AST-003 and Sunitinib have similar mechanism of action, consistent with the conclusions of previous study. At the same time, we also found that AST003 can downregulate the activities of AMPK, MKK and MKK kinases, which are located upstream of STAT3, suggesting that AST-003 can block the ERK/MKK/ MKKK/AMPK signal pathway upstream of STAT3. In addition, we also found that AST-003 could induce the up-regulation of the protein expression levels of apoptotic genes Caspase3, Caspase8, Caspase9, Bax and tumor suppressor $\mathrm{p} 53$, while inhibiting the protein expression of c-jun and Ras proto-oncogenes. The expression of mTOR and $\mathrm{Bcl}-2$ genes can also be inhibited by AST-003. Studies have shown that mTOR signaling pathway plays a key role in cell growth, protein translation, cell autophagy and metabolism, while abnormal regulation of mTOR signaling pathway is closely related to cell proliferation (19), and Bcl2 is an anti-apoptotic gene (20). Thus, the mechanism of AST-003 is similar to that of Sunitinib, but on this basis, AST-003 may act on more targets, regulate the expression of multiple genes, and block multiple signal transduction pathways, which may explain why AST-003 has a stronger efficacy than Sunitinib observed in previous study.

Since our study is still in a relatively early stage and is mainly used to verify the inhibitory effect of AST-003 on RCC cells in vitro, we did not set up a standard Sunitinib control group. The present results show that the inhibitory effect of AST-003 on RCC cells is clear and the mechanism might be similar to that of Sunitinib. Further studies will be conducted to evaluate the inhibitory effect of AST-003 on RCC in animals, and Sunitinib will be used as a standard control to understand the differences between the two in terms of efficacy and safety in animals, so as to provide sufficient evidence for subsequent human trials.

\section{Conclusions}

Overall, our study found that AST-003 could effectively promote the apoptosis of RCC cells in vitro and block the cells in the intercellular phase, and the mechanism was similar to that of Sunitinib, suggesting AST-003 has the value of further research.

\section{Acknowledgments}

Funding: This study was supported by Beijing Natural Science Foundation (7172044).

\section{Footnote}

Reporting Checklist: The authors have completed the MDAR checklist. Available at http://dx.doi.org/10.21037/tcr-203330

Data Sharing Statement: Available at http://dx.doi. org/10.21037/tcr-20-3330

Conflicts of Interest: All authors have completed the ICMJE uniform disclosure form (available at http://dx.doi. org/10.21037/tcr-20-3330). The authors have no conflicts 
of interest to declare.

Ethical Statement: The authors are accountable for all aspects of the work in ensuring that questions related to the accuracy or integrity of any part of the work are appropriately investigated and resolved. The study was conducted in accordance with the Declaration of Helsinki (as revised in 2013). This study was approved by the Ethics Committee of Peking University Cancer Hospital (2017-2-4). As this study did not contain human trials, the requirement for informed consent was waived by the Ethics Committee.

Open Access Statement: This is an Open Access article distributed in accordance with the Creative Commons Attribution-NonCommercial-NoDerivs 4.0 International License (CC BY-NC-ND 4.0), which permits the noncommercial replication and distribution of the article with the strict proviso that no changes or edits are made and the original work is properly cited (including links to both the formal publication through the relevant DOI and the license). See: https://creativecommons.org/licenses/by-nc-nd/4.0/.

\section{References}

1. Siegel RL, Miller KD, Jemal A. Cancer Statistics, 2017. CA Cancer J Clin 2017;67:7-30.

2. Kovacs G, Akhtar M, Beckwith BJ, et al. The Heidelberg classification of renal cell tumours. J Pathol 1997;183:131-3.

3. Flanigan RC, Campbell SC, Clark JI, et al. Metastatic renal cell carcinoma. Curr Treat Options Oncol 2003;4:385-90.

4. Choueiri TK, Motzer RJ. Systemic Therapy for Metastatic Renal-Cell Carcinoma. N Engl J Med 2017;376:354-66.

5. Mena AC, Pulido EG, Guillén-Ponce C. Understanding the molecular-based mechanism of action of the tyrosine kinase inhibitor: sunitinib. Anticancer Drugs 2010;21 Suppl 1:S3-11.

6. Houk BE, Bello CL, Kang D, et al. A population pharmacokinetic meta-analysis of sunitinib malate (SU11248) and its primary metabolite (SU12662) in healthy volunteers and oncology patients. Clin Cancer Res 2009; 15:2497-506.

7. Abdel-Rahman O, Fouad M. Risk of cardiovascular toxicities in patients with solid tumors treated with sunitinib, axitinib, cediranib or regorafenib: an updated systematic review and comparative meta-analysis. Crit Rev Oncol Hematol 2014;92:194-207.

8. Huang Q, Zhou C, Chen X, et al. Prodrug AST-
003 Improves the Therapeutic Index of the MultiTargeted Tyrosine Kinase Inhibitor Sunitinib. PLoS One 2015;10:e0141395.

9. Folkman J. Tumor angiogenesis: therapeutic implications. N Engl J Med 1971;285:1182-6.

10. Zwick E, Bange J, Ullrich A. Receptor tyrosine kinases as targets for anticancer drugs. Trends Mol Med 2002;8:17-23.

11. Arora A, Scholar EM. Role of tyrosine kinase inhibitors in cancer therapy. J Pharmacol Exp Ther 2005;315:971-9.

12. Karaman S, Leppänen VM, Alitalo K. Vascular endothelial growth factor signaling in development and disease. Dev Camb Engl 2018;145:dev151019.

13. Papadopoulos N, Lennartsson J. The PDGF/PDGFR pathway as a drug target. Mol Aspects Med 2018;62:75-88.

14. Faivre S, Delbaldo C, Vera K, et al. Safety, pharmacokinetic, and antitumor activity of SU11248, a novel oral multitarget tyrosine kinase inhibitor, in patients with cancer. J Clin Oncol 2006;24:25-35.

15. Escudier B, Eisen T, Porta C, et al. Renal cell carcinoma: ESMO Clinical Practice Guidelines for diagnosis, treatment and follow-up. Ann Oncol 2012;23 Suppl 7:vii65-71.

16. Abdel-Rahman O, Fouad M. Risk of mucocutaneous toxicities in patients with solid tumors treated with sunitinib: a critical review and meta analysis. Expert Rev Anticancer Ther 2015;15:129-41.

17. Bæk Møller N, Budolfsen C, Grimm D, et al. DrugInduced Hypertension Caused by Multikinase Inhibitors (Sorafenib, Sunitinib, Lenvatinib and Axitinib) in Renal Cell Carcinoma Treatment. Int J Mol Sci 2019;20:4712.

18. Speed B, Bu HZ, Pool WF, et al. Pharmacokinetics, distribution, and metabolism of [14C]sunitinib in rats, monkeys, and humans. Drug Metab Dispos 2012;40:539-55.

19. Meric-Bernstam F, Gonzalez-Angulo AM. Targeting the mTOR signaling network for cancer therapy. J Clin Oncol 2009;27:2278-87.

20. Deng H, Yue JK, Zusman BE, et al. B-Cell Lymphoma 2 (Bcl-2) and Regulation of Apoptosis after Traumatic Brain Injury: A Clinical Perspective. Medicina (Kaunas) 2020;56:300.

Cite this article as: Tang X, Zhao Q, Liu J, Wang S, Zhang N, Yang Y. The compound AST-003 could effectively promote apoptosis of renal cell carcinoma cells in vitro. Transl Cancer Res 2021;10(5):2120-2133. doi: 10.21037/tcr-20-3330 